\title{
PLANEAMENTO DE RECURSOS EDUCATIVOS EM PORTUGAL AO LONGO DOS ÚLTIMOS 80 ANOS
}

Lúcia Santos ${ }^{1}$

A. M. Rochette Cordeiro

Luís Alcoforado 3

\section{RESUMO}

Nos últimos 80 anos Portugal sofreu profundas alterações políticas, demográficas, sociais e económicas, passando de um regime ditatorial a um sistema democrático, de uma população jovem a uma população envelhecida e de uma economia rural a uma economia de serviços. Em termos educativos evoluiu de uma educação elitista em que a escolaridade obrigatória era de três anos, para uma educação para todos, durante mais tempo, em que o tempo de permanência na escola aumentou para doze anos. O planeamento de recursos educativos nem sempre se ajustou ao quadro conceptual e legislativo e às necessidades demográficas e socioeconómicas do país, mas o mais recente financiamento comunitário (2007-2013) criou condições para dar um novo impulso ao planeamento de infraestruturas e para repensar os seus pressupostos, apresentando hoje Portugal um parque escolar mais adaptado aos desafios que caracterizam a sociedade atual. Neste trabalho, que se integra num projeto de pesquisa mais alargado, procurou-se compreender o momento atual da educação em Portugal, a partir da análise dos seus principais impulsos ao longo das últimas décadas, ilustrando a relação entre as finalidades da educação, as decisões políticas e as dinâmicas sociais e o planeamento de recursos educativos através da evolução da rede escolar ao longo deste período. Este estudo baseia-se numa pesquisa documental diacrónica, focando-

1 Doutoranda em Ciências da Educação da Universidade de Coimbra. Bolseira de investigação - Foundation for Science and Technology. Mestre em Geociências. E-mail: luciarsantos@ gmail.com.

2 Professor da Faculdade de Letras da Universidade de Coimbra. Doutor em Geografia. E-mail: rochettecordeiro@fl.uc.pt.

3 Professor da Faculdade de Psicologia e de Ciências da Educação da Universidade de Coimbra. Doutor em Ciências da Educação. E-mail: lalcoforado@fpce.uc.pt. 
se em estudos de caso de territórios de alta e baixa densidade do centro de Portugal, permitindo reunir evidências de que, apesar das orientações serem nacionais, o país nem sempre evolui à mesma velocidade, existindo uma clara interferência das diferentes dinâmicas territoriais nas opções tomadas e nos resultados alcançados.

Palavras-chave: Recursos educativos. Planeamento. Resultados escolares.

\section{PORTUGUESE EDUCATIONAL RESOURCES PLANNING OVER THE PAST 80 YEARS}

\section{ABSTRACT}

In the last 80 years Portugal has suffered political, demographic, social and economic changes, from a dictatorial regime to a democratic system, from a young population to an ageing population and from a rural economy to a service economy. In terms of education, it has progressed from an education for the elites, with a compulsory education period of three years, to an education for everyone and for a longer period (compulsory education of 12 years). The planning of educational resources has not always been adjusted to the conceptual and legislative framework and to the demographic and socioeconomic needs, but the recent community funding (2007-2013) has created the conditions to give a fresh impetus to the planning of infrastructures and to rethink their assumptions and Portugal now has schools which are more well adapted to the characteristics of modern Portuguese society. This project sought to understand the state of education in Portugal through the analysis of its main tendencies in recent decades, illustrating the relation between the purpose of education, political decisions and social dynamics and the planning of educational resources through the evolution of the school network. This paper is based upon a thorough diachronic documentary research, focusing on case studies of high and low density territories in Central Portugal, which led to the gathering of evidence that, despite the national guidelines, the country has not 
progressed at an uniform rate and there is a interference of the different territorial dynamics in the choices made and in the results achieved.

Keywords: Educational resources. Planning. School results.

\section{PLANEAMIENTO DE RECURSOS EDUCATIVOS EN PORTUGAL EN LOS ÚLTIMOS 80 AÑOS}

\section{RESUMEN}

En los últimos 80 años, Portugal experimentó cambios políticos, demográficos, sociales y económicos: cambió el régimen dictatorial por un sistema democrático, una población joven por una población envejecida y una economía rural por una economía de servicios. En términos educativos evolucionó desde una educación elitista, con una escolaridad obligatoria de tres años, hasta una educación para todos y durante más tiempo (escolaridad obligatoria de 12 años). El planeamiento de los recursos educativos no siempre se ajustó al marco conceptual y legislativo y a las necesidades demográficas y socioeconómicas, pero la financiación comunitaria reciente (20072013) creó las condiciones para dar un nuevo impulso al planeamiento de las infraestructuras y para repensar sus presupuestos, permitiendo hoy a Portugal presentar estructuras educativas más adaptadas a las normas que caracterizan a la sociedad actual. Este proyecto trató de comprender la situación de la educación en Portugal a partir del análisis de las orientaciones dominantes en las últimas décadas, ilustrando la relación entre los objetivos de la educación, las decisiones políticas y las dinámicas sociales y la planificación de los recursos educativos a través de la evolución la red escolar. Este trabajo se apoya en una pesquisa documental diacrónica exhaustiva, centrándose en estudios de caso de territorios con elevada y baja densidad poblacional del centro de Portugal, lo que permite comprobar que a pesar de que las orientaciones sean nacionales, el país no evolucionó al mismo ritmo y hay una fuerte interferencia de las diferentes dinámicas territoriales en las decisiones tomadas y los resultados obtenidos. 
Palabras clave: Recursos educativos. Planeamiento. Resultados escolares.

\section{INTRODUÇÃO}

Foi durante o período ditatorial do Estado Novo (19331974) que grande parte da atual rede escolar pública portuguesa foi construída, partindo da necessidade de aproximar as escolas das populações e, desta forma, assegurar a escolaridade básica obrigatória, primeiro de três e depois de quatro anos, para todas as crianças. No entanto, quer já nos últimos anos desse regime, quer, principalmente, no período democrático, pós 1974, Portugal viveu uma profunda transformação da sua realidade demográfica, económica, social e política, refletindo os edifícios escolares e os equipamentos educativos as alterações de percurso vividas, em particular, durante o processo de transição e consolidação da democracia, mas sem conseguirem acompanhar o ritmo acelerado a que as alterações ocorreram, em muito devido à escassez de recursos financeiros, uma vez que só na primeira década do século XXI se reuniram as condições necessárias para os reequacionar, globalmente, pela primeira vez.

Vivendo-se, neste momento, em Portugal, uma fase em que o investimento em edifícios e equipamentos educativos se carateriza por um indisfarçável abrandamento, o presente projeto de investigação tem por objetivo analisar o impacto das modificações observadas, no nosso país, nos últimos 80 anos, no planeamento de espaços para o desenvolvimento da rede escolar e perceber de que forma ele se refletiu nas características dessa mesma rede, lançando as bases para perspetivar o futuro do planeamento de recursos educativos em Portugal.

De uma maneira mais específica, este trabalho assume como objeto central de estudoa rede escolar pública do $1^{\circ} \mathrm{ciclo}$ do ensino básico ( $\left.1{ }^{\circ} \mathrm{CEB}\right)$, tendo por ponto de partida uma análise diacrónica de documentos sobre o planeamento e a construção de edifícios, bem como a consolidação da rede escolar daí resultante, seguida de uma 
abordagem compreensiva baseada em três estudos de caso, recorrendo a três municípios do centro de Portugal, dois de baixa densidade (Lousã e Mortágua) e um de alta densidade (Figueira da Foz). Estes exemplos permitiram efetuar comparações entre realidades territoriais com especificidades diferenciadas, realçando as opções políticas seguidas, em termos de estruturação das diferentes respostas de base local, cruzando-as com os resultados alcançados, no que diz respeito aos desempenhos escolares dos alunos. A informação recolhida coloca-nos um conjunto significativo de interpelações, com particular incidência numa eventual presença de realidades educativas distintas, que o planeamento centralizado, mesmo recorrendo a uma descentralização de responsabilidades e competências, ainda não conseguiu minimizar decisivamente. Continuando a ser muito atual equacionar a boa utilização de recursos para continuar a planear e renovar a rede de espaços escolares, estas reflexões assumem contornos de inquestionável importância, quando sabemos que um bom planeamento e execução de recursos educativos é uma condição indispensável para uma educação que responda aos desafios e necessidades das crianças, das famílias, das diferentes comunidades e das sociedades atuais.

\section{As transformações sociais nas últimas oito décadas}

No início da década de 30, do século XX, após o primeiro período republicano, instalou-se em Portugal um regime ditatorial designado de Estado Novo, que durou mais de quatro décadas (19331974). Após este longo período voltou a estabelecer-se um sistema democrático, que depois de um processo de transição algo conturbado, se consolidou e estabilizou, mantendo-se até aos nossos dias. A revolução de 25 de abril de 1974 foi o momento que conduziu ao restabelecimento da democracia em Portugal e os anos que se seguiram marcaram o início de uma profunda transformação na sociedade portuguesa.

Aquando do início do Estado Novo, Portugal era um país jovem e com um elevado número de crianças, apresentava um carácter marcadamente rural e caracterizava-se por uma rede de acessibilidades 
profundamente deficitária. Atualmente, Portugal caminha para uma situação antagónica, apresentando uma população envelhecida, um número de nascimentos que não garante a renovação de gerações, uma economia baseada nos serviços e uma rede de acessibilidades que se desenvolveu e alastrou por todo o território. Durante este período observou-se também uma alteração dos paradigmas sociais, com a integração generalizada da mulher no mercado de trabalho e o crescimento da classe média, a que acresceu uma progressiva litoralização da população portuguesa, o que, associado ao forte êxodo migratório das décadas de $60 / 70$ do século passado, tornou amplos sectores do interior de Portugal em territórios envelhecidos e despovoados (CORDEIRO; SANTOS; CARIDADE, 2013; CORDEIRO, 2014).

Estas transformações da sociedade portuguesa exerceram uma grande pressão sobre o sistema educativo e sobre a rede escolar e induziu processos de mudança e de demanda de soluções educativas renovadas que foram procurando dar resposta às exigências que se alargavam ao ritmo do processo de desenvolvimento social em curso.

\section{Momentos chave no planeamento de recursos educativos nas últimas oito décadas}

Nos últimos 80 anos Portugal evoluiu de uma educação socializadora elitista em que a escolaridade obrigatória era, inicialmente, de três anos, "muito marcada pela promoção doutrinária de uma cidadania restrita à lógica do Estado-nação" (AFONSO, 2008, p. 61) para uma educação entendida como direito básico para todos e durante mais tempo, em que a escolaridade obrigatória aumentou para 12 anos. Passou-se de um momento, na década de 30, em que era elevado o número de crianças no $1^{\circ} \mathrm{CEB}$, mas apenas 4117 alunos atingiam o ensino superior ( $0,06 \%$ da população portuguesa), para uma fase em que a população escolar no $1^{\circ}$ CEB sofreu uma forte redução (resultado da diminuição do número de nascimentos) e o número de alunos a frequentar o ensino superior passou para 362200 indivíduos em 2014 (3,49\% da população portuguesa), tendo os estabelecimentos 
de ensino de diferentes níveis de escolaridade proliferado por todo o país (BARRETO, 2000; INSTITUTO NACIONAL DE ESTATÍSTICA, 1963). Refletindo este desenvolvimento, a taxa de analfabetismo sofreu um notável progresso, passando de 67,8\% em 1930 para 5,2\% em 2011.

Esta radical transformação é o resultado de uma profunda evolução observada ao nível da política educativa e, mais concretamente, do planeamento de recursos educativos, cujo longo percurso pode ser sintetizado em quatro momentos cruciais, cada um comportando, em si mesmo, especificidades muito próprias.

O primeiro momento de planeamento no contexto educativo português ocorreu em pleno regime ditatorial, quando o Estado Novo definiu como objetivo fazer chegar os benefícios da educação a todas as crianças através do aumento do número de escolas primárias. Esta intenção materializou-se na apresentação do plano dos centenários, em 1940, que assumiu o compromisso de pensar a rede escolar pública do $1^{\circ} \mathrm{CEB}$ de acordo com as características demográficas e geográficas do país, definindo o número de edifícios a construir, a sua tipologia e localização e o limite de alunos por sala (ALCOFORADO; CORDEIRO; FERREIRA, 2012), levando, na prática, a prosseguir o objetivo de que cada povoado, mesmo com um número reduzido de habitantes, tivesse um edifício escolar com dimensão adequada ao número de crianças. Apesar da realização longe da prevista, os 20 anos seguintes ao seu lançamento foram determinantes para a expansão da rede escolar pública do $1^{\circ} \mathrm{CEB}$, ao contribuir para a sua evolução e posterior estabilização, produzindo resultados que, em geral, chegaram até aos nossos dias (ALCOFORADO; CORDEIRO; FERREIRA, 2012).

Com o fim do Estado Novo e o advento da democracia, assinalando o início de uma nova e marcante etapa da vida do país, caraterizado pela consagração do direito à educação na Constituição da República Portuguesa de 1976 e com a publicação da Lei de Bases do Sistema Educativo em 1986, entrou-se numa fase decisiva para o planeamento de recursos educativos em Portugal, com o reconhecimento da sua importância e com a obrigatoriedade de 
elaboração e apresentação da carta escolar, como metodologia a seguir. Este impulso advém da necessidade de adaptar a rede escolar pública do $1^{\circ}$ CEB às alterações entretanto ocorridas na sociedade e às exigências da reforma educativa, mas também da adesão de Portugal à Comunidade Económica Europeia, que criou, novamente e de forma decisiva, condições para uma política concertada e global de planificação e disponibilização de recursos educativos (ALCOFORADO; CORDEIRO; FERREIRA, 2012). Esta fase corresponde à primeira tentativa de transformação da rede escolar pública do $1^{\circ}$ CEB após o plano dos centenários, da década de quarenta do século $\mathrm{XX}$, e corporizou uma primeira iniciativa de transferência de competências para o poder local no domínio da educação.

Mas esta medida não teve o reflexo esperado e, alguns anos mais tarde, foi publicada a Lei n. ${ }^{\circ} 159 / 99$ de 14 de setembro, que, concretizando os princípios da descentralização administrativa e da autonomia do poder local, atribuiu aos municípios a responsabilidade de elaboração da sua própria carta escolar. Embora tenha representado uma nova vontade política, uma vez mais não passou do campo da intenção e a verdade é que Portugal, já em pleno século XXI apresentava Edifícios escolares cada vez mais incapazes de responder aos crescentes desafios que era necessário e urgente colocar ao seu sistema educativo. As condições para as necessárias mudanças só ocorreram com a publicação do Decreto-lei n. ${ }^{\circ}$ 7/2003 de 15 de janeiro, que impôs aos municípios a obrigatoriedade de elaboração da carta educativa, ao regular os respetivos critérios e processos de elaboração e aprovação e ao definir os efeitos esperados. Enquanto instrumento municipal de ordenamento e planeamento prospetivo de edifícios e equipamentos educativos, a carta educativa, criou condições para que os municípios se pudessem afirmar como autores e participantes na reorganização da sua rede escolar pública do $1^{\circ}$ CEB (CORDEIRO; MARTINS; FERREIRA, 2014). Dado o avultado investimento que exigia, apenas se concretizou quando o Governo anunciou o financiamento necessário, através do Quadro de Referência Estratégico Nacional 2007-2013, que canalizava, para este fim, recursos financeiros disponibilizados pela União Europeia. É assim que, após duas tentativas falhadas, pela primeira vez, após o 
plano dos centenários, se volta a reequacionar racionalmente a rede escolar pública do $1^{\circ} \mathrm{CEB}$ em Portugal.

O atual parque escolar público português, do $1^{\circ} \mathrm{CEB}$, traduz, assim, as marcas das opções que foram sendo tomadas em contextos de permanente evolução política, demográfica, social e económica. Representa, também, relembrando os contributos de Afonso (2008), opções de políticas educativas que foram, sucessivamente, oscilando entre iniciativas de normalização capitalista e de neoliberalismo mitigado, de assunção dos valores fundacionais das ideologias mais orientadas com a filosofia da denominada terceira via e a emergência de alguns assomos neoconservadores, para revelar alguma tendência estabilizadora em opções desenvolvimentistas e racionalizadoras, com a ideia de qualidade como denominador comum. Assim, se os critérios de resposta e a localização dos espaços educativos se alteraram significativamente, as características do edificado transformaram-se por completo. De escolas de pequena dimensão, dispersas, fechadas sobre si próprias, de nível de ensino único, com salas de aula partilhadas por mais do que um ano de escolaridade em simultâneo (maioritariamente uma ou duas salas de aula), a funcionar em regime de monodocência e sem espaços complementares de apoio (bibliotecas, equipamentos desportivos e refeitórios/polivalentes), passamos a escolas de dimensões superiores, centralizadas, desejavelmente abertas à comunidade, com diferentes níveis de ensino, com uma sala de aula e um professor por cada ano de escolaridade (mínimo de quatro salas de aula) e dotadas de espaços complementares de apoio.

\section{Estudo comparativo entre opções autárquicas e discussão de resultados}

Para melhor compreender o percurso do planeamento de recursos educativos nos últimos 80 anos em Portugal parece interessante analisar os casos específicos de três municípios do centro de Portugal: Lousã, Mortágua e Figueira da Foz (Mapa 1). Os dois primeiros são territórios de características bastante idênticas. Ambos situados no centro interior, em zonas periféricas e montanhosas, distinguem-se 
apenas pela dimensão territorial e pela dinâmica demográfica. Lousã, de menor extensão territorial, apresentava 17604 habitantes em 2011 e registou um crescimento populacional bastante significativo na última década (1851 residentes, valor correspondente a 11,75\%), crescimento explicável pela proximidade à cidade de Coimbra, principal pólo urbano da região centro (o baixo preço da habitação fez deste município tender para um "dormitório" de Coimbra). Por sua vez, no mesmo período, Mortágua, apesar da maior extensão territorial, apresenta quase metade da população residente (9607 habitantes) e verificou decréscimo populacional (-772 indivíduos, valor que representa -7,44\%). Em oposição, Figueira da Foz situa-se no centro litoral e apresenta 62125 habitantes em 2011. Mas a sua localização privilegiada não o impediu de registar um muito pequeno decréscimo populacional na última década (-476 habitantes, valor correspondente a $-0,76 \%)$, o que tem na sua origem o vincado contraste observado entre o centro urbano de alta densidade, que se tem desenvolvido ao ritmo das regiões litorais, e o mundo rural de baixa densidade, a perder população e com elevados índices de envelhecimento.

Mapa 1 - Enquadramento territorial dos municípios da Lousã, Mortágua e Figueira da Foz na região centro de Portugal

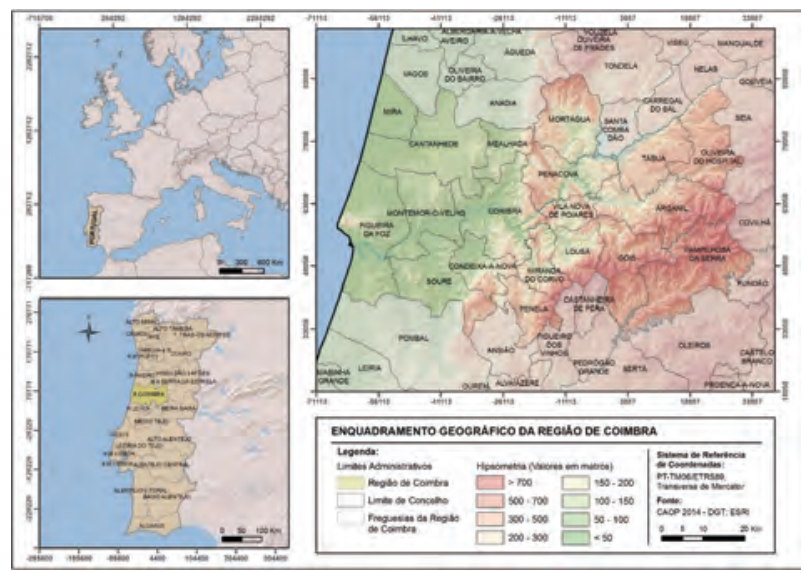

Fonte: Elaboração própria a partir de: Carta Administrativa Oficial de Portugal (CAOP) e DireçãoGeral do Território. 
Os municípios de Lousã, Mortágua e Figueira da Foz, cujas redes escolares públicas do $1^{\circ} \mathrm{CEB}$ foram concretizadas aquando do plano dos centenários, chegaram ao final do século XX com um conjunto de edifícios, na sua maioria obsoletos. Perante esta realidade, no início do século XXI, logo após a publicação do Decreto-lei n. ${ }^{\circ}$ 7/2003 de 15 de janeiro e do anúncio de financiamento comunitário, as autarquias promoveram a elaboração das suas cartas educativas (Lousã em 2005, Figueira da Foz em 2006 e Mortágua em 2007), no sentido de resolver os problemas de desajustamento, manutenção e governabilidade da rede escolar pública do $1^{\circ} \mathrm{CEB}$ que se vinham a adensar desde a década de 70 (MATTHEWS et al., 2009; RODRIGUES, 2010; CORDEIRO; MARTINS, 2013; CORDEIRO; MARTINS; FERREIRA, 2014). Mas, embora as orientações a seguir para a elaboração das cartas educativas tenham sido definidas a nível nacional pelo Ministério da Educação, tendo sido publicados, além da legislação específica, vários documentos orientadores, as propostas apresentadas nem sempre tiveram em consideração, pressupostos idênticos.

No município de Mortágua a proposta de reorganização da rede escolar apresentada pela carta educativa (CÂMARA MUNICIPAL DE MORTÀGUA, 2007) reflete os princípios defendidos e legislados pelo Ministério da Educação, com o encerramento de todas as escolas (13 escolas) e a construção de um centro escolar (Mapa 2). Localizado no setor central do território, de modo a facilitar o acesso e a diminuir o tempo de deslocação das crianças, este centro escolar foi planeado de acordo com a política de escola a tempo inteiro, oferecendo condições para que as crianças pudessem permanecer ao longo de todo o dia, como refeitório, biblioteca, espaços de desporto e áreas polivalentes. Com esta opção a autarquia garantiu a todos os alunos do território municipal igualdade de acesso a edifícios e equipamentos educativos de qualidade igual ou superior à encontrada em qualquer outro município, incluindo os grandes centros urbanos. Pode considerar-se que, neste caso, a reorganização da rede escolar pertence ao tipo "decretado", que ocorre quando as decisões dos atores locais têm total correspondência com os critérios e objetivos definidos centralmente (CORDEIRO; MARTINS, 2013; CORDEIRO; MARTINS; FERREIRA, 2014). 
Mapa 2 - Rede escolar de Mortágua: (a) antes da carta educativa; (b) depois da carta educativa

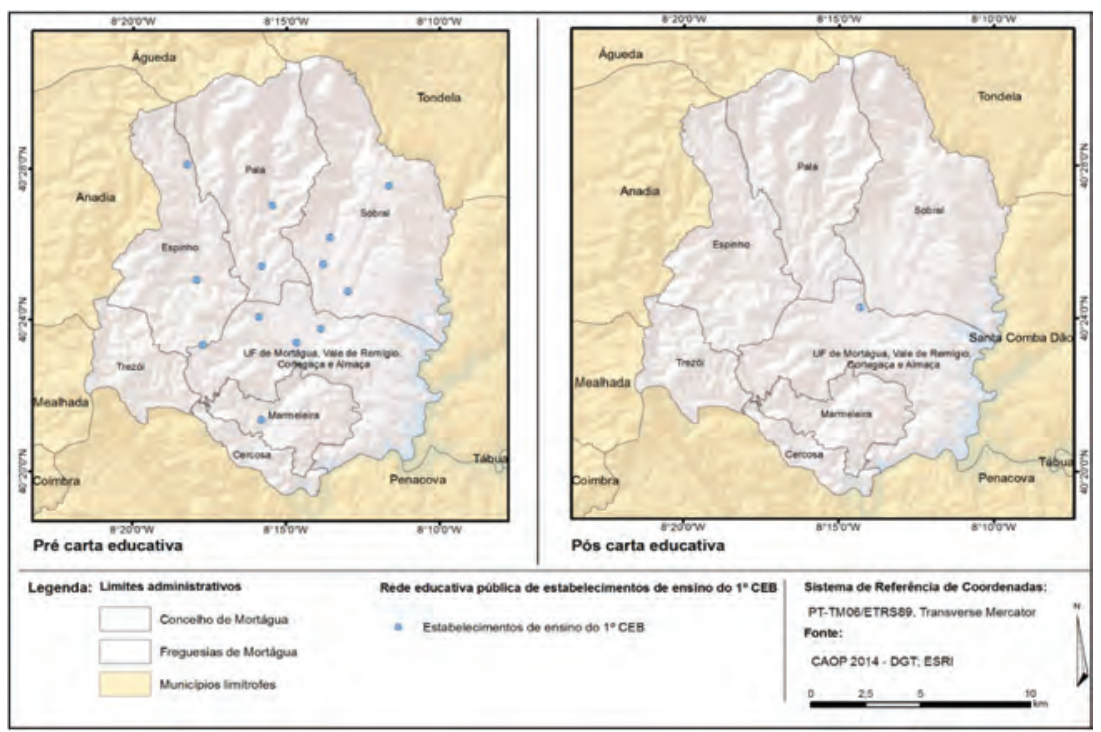

Fonte: Elaboração própria a partir de: Carta Administrativa Oficial de Portugal (CAOP) e DireçãoGeral do Território.

No município da Lousã a proposta de reorganização da rede escolar apresentada pela carta educativa optou pela manutenção da rede escolar existente na sua quase totalidade (12 escolas), propondo apenas o encerramento de duas escolas, devido ao reduzido número de alunos, e a construção de uma escola básica integrada, cujo principal objetivo era responder às necessidades identificadas no território municipal ao nível do $2^{\circ}$ e $3^{\circ}$ CEB (Mapa 3). Segundo a autarquia, esta proposta baseou-se em critérios de racionalidade, relacionados com a gestão dos dinheiros públicos, mas também numa opção de respeitar a importância que a história individual e simbologia de cada edifício assume para a população local (CÂMARA MUNICIPAL DA LOUSÃ, 2005). Ainda assim, para que as escolas pudessem oferecer, a médio prazo, condições físicas de qualidade, de acordo com as normas relativas a edifícios educativos definidas pelo Ministério da Educação, foram previstas a realização de pequenas obras de requalificação, planeadas em intervenções únicas ou em programas de intervenção 
faseados (CÂMARA MUNICIPAL DA LOUSÃ, 2005). Mais recentemente, o município promoveu uma revisão da sua carta educativa (FACULDADE DE LETRAS DA Universidade de Coimbra, 2015) que reequaciona alguns dos pressupostos da carta anterior, com implicações práticas em termos de organização da rede (Mapa 3).

Mapa 3 - Rede escolar da Lousã: (a) antes da carta educativa; (b) depois da carta educativa; (c) proposta após revisão recente da carta educativa

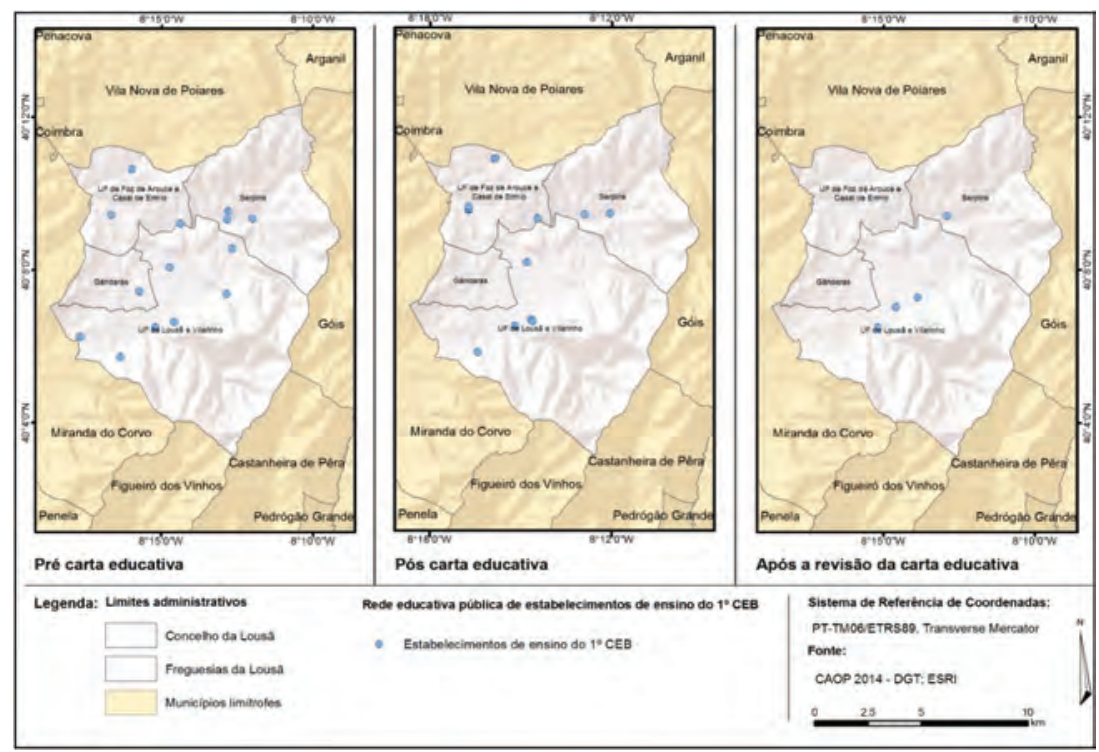

Fonte: Elaboração própria a partir de: Carta Administrativa Oficial de Portugal (CAOP) e Direção-Geral do Território.

Com uma rede escolar de dimensão bastante superior aos dois exemplos anteriores (59 escolas), no município da Figueira da Foz a proposta de reorganização da rede escolar apresentada pela carta educativa seguiu uma estratégia de intervenção faseada e assente na definição de 10 territórios educativos, que serviram de suporte ao planeamento da rede escolar, ainda que alguns fossem servidos por mais do que uma escola em simultâneo (FACULDADE DE LETRAS DA UNIVERSIDADE DE COIMBRA, 2006). Com base nestes pressupostos, na fase final propôs a criação de 9 centros escolares (maioritariamente através da realização de obras de requalificação e ampliação) e a 
manutenção de 7 escolas (apenas duas com realização de obras de requalificação), tendo sido os necessários encerramentos planeados para ocorrer de forma gradual, em função das condições físicas e dinâmica natural de cada escola (Mapa 4).

Mapa 4 - Rede escolar da Figueira da Foz: (a) antes da carta educativa; (b) depois da carta educativa; (c) organização atual

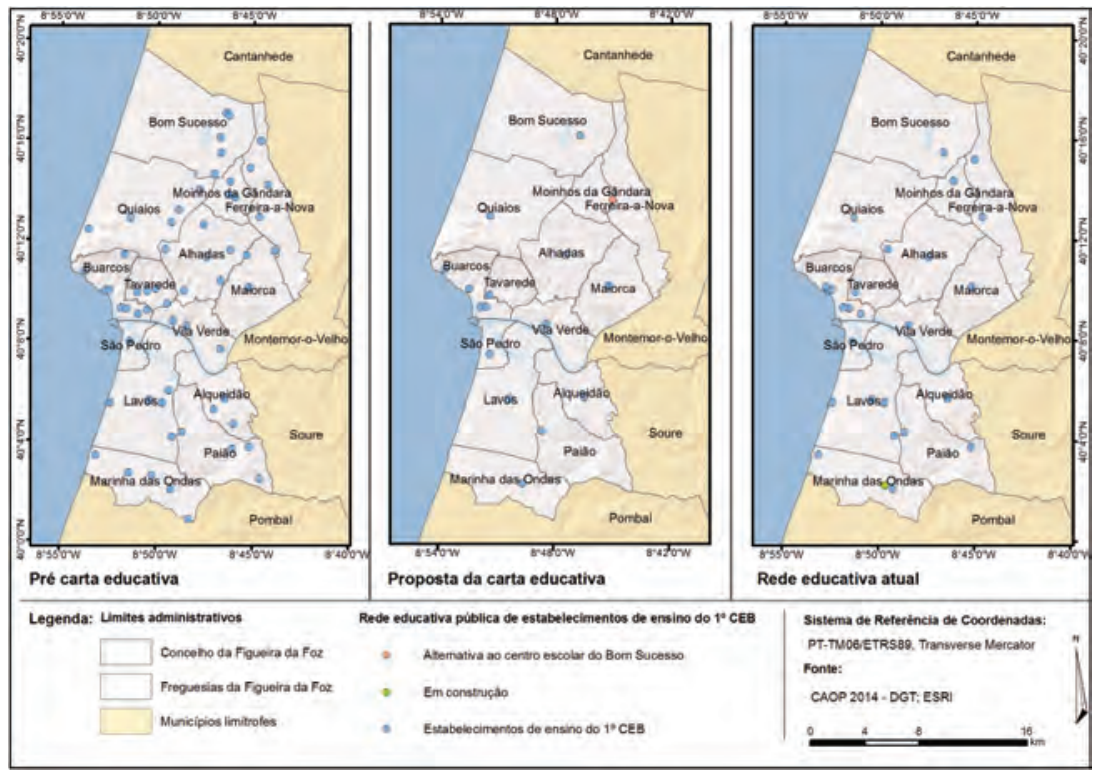

Fonte: Elaboração própria a partir de: Carta Administrativa Oficial de Portugal (CAOP) e Direção-Geral do Território.

Ainda que a rede escolar do município da Figueira da Foz tenha sofrido uma redução bastante mais significativa que a observada no município da Lousã, em grande parte devido à sua dinâmica natural, que determinou um encerramento mais tardio das escolas de pequena dimensão, em ambos os casos a distribuição geográfica e a tipologia de edifícios sofreu alterações estruturais pouco significativas com a reorganização da rede escolar proposta pela carta educativa. Apostou-se numa rede escolar de proximidade, com a manutenção em funcionamento de escolas de pequena dimensão, não tendo existido 
um significativo aumento do número de alunos em movimento, nem um investimento forte na tipologia de centro escolar, de maiores dimensões e valências integradas (CORDEIRO; MARTINS; FERREIRA, 2014), não tendo sido salvaguardada a criação de condições de igualdade de acesso e desenvolvimento de atividades educativas para todos os alunos, nestes dois territórios municipais. A reorganização da rede escolar adotada parece, assim, equivaler ao tipo "comunitário", que se verifica quando as reivindicações e decisões dos atores locais se sobrepõem ou ignoram os critérios e objetivos definidos centralmente (CORDEIRO; MARTINS, 2013; CORDEIRO; MARTINS; FERREIRA, 2014).

Passada quase uma década após a realização das cartas educativas o cenário é, como se pode verificar, bastante distinto nos três municípios em análise. Enquanto no município de Mortágua a reorganização da rede escolar ainda se mantém perfeitamente ajustada, não existindo necessidade de revisão das propostas apresentadas, nos outros dois municípios a realidade é bem diferente. No município da Lousã a proposta apresentada e executada, através da carta educativa, conduziram a uma situação de evidente desadequação da rede escolar. Perante a consciencialização da urgência em conceder novas soluções e oportunidades às crianças, ao longo do $1^{\circ} \mathrm{CEB}$, a autarquia reequacionou, recentemente, as bases de elaboração da sua carta e promoveu um processo circunstanciado de revisão. Concluído em 2015, os critérios de programação agora seguidos foram significativamente distintos dos iniciais, tendo optado por acompanhar o movimento nacional predominante, de modernização da rede escolar, que na prática se traduziu na concentração da população escolar em quatro escolas e no encerramento das restantes escolas (9 escolas). Em situação oposta, o município da Figueira da Foz continua a assumir como documento orientador da política educativa a carta educativa aprovada em 2006, o qual teve, como ficou demonstrado, um grau de implementação bastante baixo. Apenas foi construído um centro escolar de grande dimensão no centro urbano e um outro de pequena dimensão no espaço periurbano oriental, a que acresceu o encerramento de algumas escolas de pequena dimensão. Foram ainda realizados trabalhos pontuais de requalificação e ampliação de escolas, limitados às salas de aula, não se 
tendo observado intervenções no sentido de equipar os edifícios com espaços complementares de apoio.

Os resultados deste estudo levam-nos a perceber que não devemos ser tentados por interpretações simplistas. Se numa análise unicamente baseada nos indicadores apresentados, seriamos impelidos a acreditar que as discrepâncias encontradas ao nível das propostas de reorganização da rede escolar estariam relacionadas com os diferentes contextos territoriais e que seriam os municípios mais dinâmicos a manifestar maior preocupação com a modernização da rede escolar, numa análise mais fundamentada nas idiossincrasias de casos concretos somos forçados a constatar que as divergências têm na sua origem maioritariamente questões políticas, quer ideológicas, que aproximam ou afastam as autarquias locais das indicações nacionais, criando níveis de aceitação e de resistência distintos, quer de visão estratégica, que interfere de forma significativa na definição da orientação e dos objetivos da política educativa local. Ainda que, muitas vezes, estas questões possam ser ultrapassadas com a existência de equipas técnicas de educação de elevada capacidade de análise e intervenção, capaz de influenciar a decisão política, apresentasse-nos muito natural que os decisores procurem atender, em cada momento, às aspirações e reivindicações dos atores e comunidades locais que, no limite, vão resistindo ao abandono de respostas de maior proximidade, mesmo quando as condições de desenvolvimento das atividades educativas, entendidas no sentido mais alargado do termo, poderiam ser amplamente melhoradas.

Será, por isso mesmo, muito importante desenvolver estudos que nos permitam identificar e caracterizar as implicações para as aprendizagens e desenvolvimento pessoal e social das crianças que as diferentes opções autárquicas podem implicar. Dito de outra forma, será indispensável procurar compreender se os motivos que estiveram na base da escolha de caminhos tão distintos, com implicações concretas para o tipo de reorganização da rede escolar efetuada, se reflete na qualidade das respostas de educação e formação, nos diferentes espaços territoriais e, consequentemente, nos percursos educativos dos(as) 
alunos(as), objetivo que deverá sempre orientar o planeamento de recursos educativos. Para isso pareceu-nos pertinente elaborar, para este trabalho em concreto, uma breve interpelação aos resultados obtidos pelos alunos no final do primeiro ciclo de quatro anos de escolaridade, nas provas nacionais, realizadas no final do ano letivo de 2014/2015, procurando entendê-los, também, à luz das opções de organização da rede educativa. Temos, naturalmente, consciência de que se trata apenas de um indicador, entre vários outros, que nos poderão permitira emissão de um juízo sobre a igualdade de acesso e sucesso. Temos, igualmente, noção que necessitaríamos de uma monitorização mais continuada, em diferentes anos, destes mesmos resultados, para que o juízo a emitir pudesse ser mais rigoroso, mas, mesmo assim, parece-nos um exercício de inegável valor heurístico e explicativo, apresentando-o, por isso mesmo, de seguida.

$\mathrm{Na}$ verdade, um estudo realizado em 2015, pela Universidade de Coimbra, para a Comunidade Intermunicipal Região de Coimbra (CORDEIRO e ALCOFORADO, 2015), sobre prevenção do abandono escolar e promoção da igualdade ao longo dos percursos educativos no ensino básico, permite estabelecer uma eventual relação entre o tipo de reorganização da rede escolar efetuada e os últimos resultados escolares disponíveis pelos alunos nas provas nacionais de final de ciclo, nos anos letivos de 2013/2014 e 2014/2015. Do conjunto dos 19 municípios que integram a Comunidade Intermunicipal Região de Coimbra, o estudo revela que para os dados de 2013/2014 (mais fiáveis devido a questões meramente políticas) o município de Mortágua é aquele que apresenta o $2^{\circ}$ melhor lugar ao nível dos resultados dos exames nacionais de $4^{\circ}$ ano, seguindo-se o município da Figueira da Foz, que ocupa o $8^{\circ}$ lugar, e o município da Lousã, que aparece em $18^{\circ}$ lugar (Tabela 1). Se as diferenças ao nível do tipo de reorganização da rede educativa implementada poderiam explicar o posicionamento do município de Mortágua e o distanciamento deste em relação aos outros dois territórios, o mesmo argumento não explica, naturalmente, o número de lugares que separam os municípios da Figueira da Foz e da Lousã. Neste caso poderá aventar-se a explicação da existência de uma 
clara diferença de dinamismo demográfico e socioeconómico entre os dois territórios, que, no caso do município da Figueira da Foz, funciona como elemento explicativo, em termos das opções tomadas em relação à rede escolar.

Tabela 1 - Média dos exames nacionais de 4º ano em 2013/2014

\begin{tabular}{|c|c|c|c|}
\hline Municípios & $\begin{array}{c}\text { Exames } 4^{\circ} \text { ano } \\
n^{\circ}\end{array}$ & $\begin{array}{c}\text { Média exames } \\
\%\end{array}$ & Posição \\
\hline Mortágua & 110 & 65,7 & $2^{\mathrm{o}}$ \\
\hline Figueira da Foz & 1021 & 59,7 & $8^{\circ}$ \\
\hline Lousã & 303 & 54,1 & $18^{\circ}$ \\
\hline Região de Coimbra & 7319 & 59,4 & - \\
\hline
\end{tabular}

Fonte: Cordeiro e Alcoforado, 2015.

A realidade, tal como resulta da posição relativa dos municípios, em resultado das médias obtidas nas provas nacionais, pode ser corroborada por uma análise mais compreensiva e diferenciada desses mesmos resultados (Tabela 2), sendo o município de Mortágua aquele que regista a menor percentagem de desempenhos em exames nacionais de $4^{\circ}$ ano com classificação menos positiva (= ou < 50\%). Do mesmo modo, é também o território municipal que verifica o menor número de exames com classificação de valores mais baixos (= ou < $35 \%$ ) e o que observa o maior número de exames com classificação mais elevada (= ou $>80 \%$ ). 
Tabela 2 - Exames nacionais de $4^{\circ}$ ano segundo a classificação no ano letivo de 2013/2014

\begin{tabular}{|c|c|c|c|c|c|c|c|}
\hline \multirow{3}{*}{ Municípios } & \multicolumn{2}{|l|}{ Exames $4^{\circ}$ ano } & \multicolumn{3}{|c|}{ Média exames } & \multirow{2}{*}{\multicolumn{2}{|c|}{ ou $>80 \%$}} \\
\hline & $n^{\circ}$ & $=\mathrm{ou}<$ & $<35 \%$ & $=\mathrm{ou}<$ & $50 \%=$ & & \\
\hline & $\mathrm{n}$ & $\mathrm{n}^{\mathrm{o}}$ & $\%$ & $\mathrm{n}^{\mathrm{o}}$ & $\%$ & $\mathrm{n}^{\mathrm{o}}$ & $\%$ \\
\hline Mortágua & 110 & 5 & 4,5 & 14 & 12,7 & 22 & 20,0 \\
\hline Figueira da Foz & 1021 & 116 & 11,4 & 292 & 28,6 & 159 & 15,6 \\
\hline Lousã & 303 & 45 & 14,9 & 111 & 36,6 & 36 & 11,9 \\
\hline Região de Coimbra & 7319 & 825 & 11,3 & 1981 & 27,1 & 1396 & 19,1 \\
\hline
\end{tabular}

Fonte: Cordeiro e Alcoforado, 2015.

Reafirmando que apenas se pretendeu elaborar uma breve análise dos resultados escolares, numa relação direta com algumas opções de gestão de rede, tomadas recentemente, sem com esse exercício pretender generalizar conclusões e retirar implicações que seriam de todo, abusivas, parece, no entanto, possível reunir algumas evidências capazes de nos sugerir que, apesar de todo este processo ter tido como princípio base a redução das assimetrias existentes no território nacional e a criação de condições de igualdade de acesso a uma educação que seja capaz de garantir os princípios de base para todos disporem dos mesmos meios e condições, este objetivo não parece estar a ser alcançado por completo e a verdade é que Portugal pode estar a continuar a criar condições para a organização uma educação pública a diferentes velocidades. Confirmando, igualmente, que os resultados das provas nacionais são apenas um indicador, eventualmente nem sequer o mais importante, que nos permite avaliar com o rigor possível, as políticas, organização e evolução das respostas educativas, ao nível nacional e local, sempre será possível dizer que os números aqui coligidos, necessitando de processos mais longos de monitorização, parecem indicar que a opção por estabelecimentos mais integrados, funcionando sempre como resposta de proximidade, 
capazes de reunir os meios de proporcionar uma escola a tempo inteiro, com atividades diversificadas, revelam alguma tendência para uma contribuição positiva para a obtenção de melhores resultados dos(as) alunos(as), nas provas nacionais.

\section{Considerações finais}

Fruto da consciencialização do papel da educação no desenvolvimento social e da necessidade de acompanhar a evolução registada na sociedade, Portugal tem vindo a manifestar uma preocupação crescente com o planeamento de recursos educativos, estabelecendo normativos com vista a assegurar a coerência nacional do sistema educativo.

As opções políticas que se podem identificar nesta vontade parecem, no essencial, corretas. Partindo de um conjunto de orientações centralizadas que definem critérios de organização da rede e de financiamento para a sua execução, abre-se espaço para um protagonismo das comunidades e decisores locais, a quem cabe, em última análise, a deliberação final sobre as soluções que desejam para os seus espaços territoriais. Estas opções serão sempre o ponto de encontro, mas também de tensão, entre interesses diversos e propostas com a fundamentação técnica possível, que se vai resolvendo na lógica de vontades prevalecentes em determinados momentos. Por isso mesmo, é fundamental acompanhar estas decisões por estudos que ajudem a clarificar as diferentes situações e a suportar novas decisões políticas de base local.

As evidências aqui reunidas permitem concluir que a procura de um salto qualitativo para a educação em Portugal poderá sair, frequentemente, afetada, em resultado de uma reorganização da rede educativa equacionada, muitas vezes, sem atender a uma lógica de caráter predominantemente técnico, suportando-se, em muitos casos, em opções de estratégias locais, nem sempre consentâneas com a realidade e as necessidades das pessoas e das comunidades, estando, 
por isso mesmo, mais exposta à criação de algumas dimensões possíveis de gerar desigualdades entre diferentes territórios e, até, dentro de um mesmo território. Será, acima de tudo, muito importante, que qualquer decisão que possa ser tomada, envolva sempre as opções necessárias para melhorar as condições de estudo, aprendizagem e desenvolvimento pessoal e social das crianças, em detrimento de alguns modismos como a qualidade e a racionalização, que, muitas vezes, inundam a retórica que justifica as decisões implementadas.

Apesar de tudo, embora com respostas raramente atempadas e assumidas como prioritárias, não será difícil concluir que o planeamento de recursos educativos foi reagindo à complexificação do pensamento educativo e das formas sociais de vida, tendendo a apresentar, hoje, Portugal, uma rede escolar pública do $1^{\circ}$ CEB modernizada, com novas tipologias de estabelecimentos e edifícios muito adequados.

\section{Referências}

AFONSO, A. Políticas Educativas Contemporâneas: dilemas e desafi os. In CUNHA, N. F. (Org.). Pedagogia e Educação em Portugal, Séculos XX e XXI. Vila Nova de Famalicão: CMVNF, 2008. p. 61-80.

ALCOFORADO, J. L. M.; CORDEIRO, A. M. R.; FERREIRA, S. M. A (re) organização da rede escolar como refl exo das transformações demográfi cas, políticas e geográfi cas, nas últimas seis décadas em Portugal. In: MOGARRO, M. J.; CUNHA, M.T.S. (Orgs.). Rituais, Espaços \& Patrimónios Escolares. Lisboa: Instituto de Educação da Universidade de Lisboa, 2012. p. 5423-5435.

BARRETO, A. A situação social em Portugal 1960-1999. Lisboa: Imprensa de Ciências Sociais, 2000.

CÂMARA MUNICIPAL DA LOUSÃ. Carta educativa da Lousã. Lousã: Câmara Municipal da Lousã, 2005.

CÂMARA MUNICIPAL DE MORTÁGUA. Carta educativa de Mortágua. Mortágua: Câmara Municipal de Mortágua, 2007. 
CORDEIRO, A. M. R. E ALCOFORADO, L. (Coords.). Programa intermunicipal de prevenção do abandono escolar e promoção da igualdade de acesso ao ensino da comunidade intermunicipal região de Coimbra. Coimbra: Faculdade de Letras da Universidade de Coimbra, 2015.

CORDEIRO, A. M. R. O lugar dos municípios no planeamento e gestão da rede escolar em Portugal. In: RODRIGUES, M. L. (Coord.). 40 Anos de Políticas de Educação em Portugal: A Construção do Sistema Democrático de Ensino. Coimbra: Almedina, 2014. p. 421-444.

CORDEIRO, A. M. R.; MARTINS, H. A.; FERREIRA, A. G. As cartas educativas municipais e o reordenamento da rede escolar no Centro de Portugal: das condições demográfi cas às decisões políticas. Revista Ensaio, Rio de Janeiro, v. 22, n. 84, 2014.

CORDEIRO, A. M. R.; MARTINS, H. A. A Carta Educativa Municipal como instrumento estratégico de reorganização da rede educativa: tendências de mudança. Cadernos de Geografi a, Coimbra, n. 32, 2013.

CORDEIRO, A. M. R.; SANTOS, L.; CARIDADE, P. A Reorganização do Parque Escolar Nacional e a importância das componentes geográfi cas na metodologia adotada. Cadernos de Geografi a, Coimbra, n. 32, 2013.

FACULDADE DE LETRAS DA UNIVERSIDADE DE COIMBRA. Carta educativa da Figueira da Foz. Coimbra: Faculdade de Letras da Universidade de Coimbra, 2006.

FACULDADE DE LETRAS DA UNIVERSIDADE DE COIMBRA. Revisão da carta educativa da Lousã. Coimbra: Faculdade de Letras da Universidade de Coimbra, 2015.

INSTITUTO NACIONAL DE ESTATÍSTICA. X Recenseamento Geral da População - Tomo II. Lisboa: Instituto Nacional de Estatística, 1963.

INSTITUTO NACIONAL DE ESTATÍSTICA.Dados referentes à educação em Portugal Disponível em: < http://www.ine.pt >. Acesso em: 06 jun.2016. 
PORTUGAL. Lei no 159/99, de 14 de setembro. Estabelece o quadro de transferência de atribuições e competências para as autarquias locais. Diário da República, Lisboa, 14 set. 1999.

MATTHEWS, P. et al. Política educativa para o $1^{\circ}$ ciclo do ensino básico 2005-2008. Avaliação Internacional. Lisboa: Gabinete de Estatística e Planeamento da Educação - Ministério da Educação, 2009.

PORDATA: Dados referentes à educação em Portugal. Disponível em: < http://www.pordata.pt>. Acesso em:20 jun.2016.

RODRIGUES, M. L. A Escola Pública Pode Fazer a Diferença. Coimbra: Almedina, 2010. 